\title{
Temperature Control of Flat-panel Airlift Photobioreactors for Microalgae Prduction - A Numerical Investigation
}

\author{
Polycarpos Polycarpou \\ Agricultural Research Institute, Production Division, Nicosia, Cyprus
}

Email address:

p.polycarpou@arinet.ari.gov.cy

\section{To cite this article:}

Polycarpos Polycarpou. Temperature Control of Flat-panel Airlift Photobioreactors for Microalgae Production - A Numerical Investigation. International Journal of Energy and Power Engineering. Vol. 8, No. 6, 2019, pp. 79-87. doi: 10.11648/j.ijepe.20190806.12

Received: October 23, 2019; Accepted: November 14, 2019; Published: December 6, 2019

\begin{abstract}
Within the blue biotechnology, the cultivation of microalgae has an important role. Aimed is the production of valuable bio products, including biofuels. Microalgae can be cultivated in open raceway ponds or in different types of photobioreactors (PBRs). Besides their higher investment costs, PBRs are gaining more importance due to the possibilities they offer for controlling the production parameters like, light, $\mathrm{pH}$, Nutrients, $\mathrm{CO}_{2}$ supply, etc. This study presents the influence of temperature control on the operating cost of a culture in a flat-panel airlift photobioreactor, based on a simulation model. The data used are those of a coastal range in Cyprus, at Zygi, with mild climate, requiring heating in Winter and cooling in the Summer. Microalgae grow optimally between $20^{\circ} \mathrm{C}$ and $24^{\circ} \mathrm{C}$, but choosing the right set temperatures for Winter and Summer plays an important role in the economy of the system. The most energy saving option seems to be that of a stepwise set-temperature control, with a temperature varying in steps between 19 and $24^{\circ} \mathrm{C}$ that are considered to be economic acceptable minimum and maximum values. For the estimation of the yearly fuel consumption of the PBR a new term, the Burner ON Ratio was introduced.
\end{abstract}

Keywords: Microalgae Cultivation, Photobioreactor, Biofuels, Temperature Control of Photobioreactors, Burner on Ratio

\section{Introduction}

Microalgae have become an important feedstock for biodiesel production due to their high lipid content, as they can grow rapidly, giving high yield per unit area [1, 2]. Microalgae can multiply faster than any other plants on land. They can be selected and cultivated to have a high protein and oil content, which can be used to produce biofuels or animal feeds. Furthermore, microalgal biomass that is rich in micronutrients, is also used for human dietary and health supplements, or can be cultivated to produce a variety of products like biodegradable plastics, chemical feedstock, colour pigments, lubricants, fertilizers, and cosmetics. Another benefit is that they can grow without competing with agriculture on land threatening food supply.

There are more than 35,000 different types of microalgae containing $18 \%$ to $50 \%$ of lipids in their biomass $[3,4]$ that makes them suitable for biodiesel production. Microalgae can be cultivated using various water resources such as brackish-, sea-, and wastewater that is unsuitable for cultivating agricultural crops.

Microalgae require light, carbon dioxide, appropriate temperature, $\mathrm{pH}$ and nutrient elements to produce biomass by photosynthesis. Light supplies the energy for photosynthesis whereas carbon dioxide acts as carbon source for the biomass generation [5]. Carbon is required since the microalgae biomass contains about $45 \%$ to $50 \%$ of it [3]. Since the natural $\mathrm{CO}_{2}$ concentration $(0.03 \%)$ in ambient air is too low to supply the necessary carbon needed for optimal growth and high biomass productivity, additional carbon dioxide is needed to accelerate the growth of microalgae [4]. Thus, carbon rich sources can be obtained from industrial exhaust gases that contain more than $13 \% \mathrm{CO}_{2}$, like fossil fuel combustion and other biological processes such as biogas or biochar production, provided they are cleaned so as to be free from harmful gases like $\mathrm{CO}, \mathrm{SO}_{2}$, etc. In this way microalgae can help recycle $\mathrm{CO}_{2}$, and help reduce greenhouse gas emissions by transforming it to biofuels and other useful products.

In order to achieve ideal growth of microalgae, the cultivation temperature should be maintained at $20^{\circ} \mathrm{C}$ to $30^{\circ} \mathrm{C}$ depending on the specific strain [6]. Normally, the microalgae biomass production will increase when temperature rises within a certain strain defined range [3]. This range is more robust when cultivating multi-algae blooms [4]. 


\subsection{Microalgae Cultivation System}

\subsubsection{Raceway or Open Pond}

Microalgae can grow in a wide variety of climates in various production methods, from open ponds to photobioreactors. They can grow in the sea, or even on land with seawater, or in nutrient-rich waters like municipal waste waters (sewage), animal wastes and industrial effluents, at the same time purifying these wastes while producing a biomass suitable for biofuels or other products production. The aim of research or industrial applications is to maximize algae growth for production of fuel, chemicals or other industrial products minimizing at the same time the production costs.

There are three types of cultivation systems used to grow microalgae, which are the open raceway ponds, the closed photobioreactors and a combination of the two. The open raceway pond is more cost effective than a closed photobioreactor and it is more suitable to be used, as an intermediate stage, in water purifying plants, to remove nutrients like nitrogen and phosphor from domestic wastewater [7]. The open pond system for microalgae cultivation can be further classified into natural water ponds and artificial ponds [8]. Generally, the raceway pond is equipped with a paddle wheel to ensure that the microalgae are kept constantly floating and circulating [9]. Although the open raceway pond system presents a lower capital cost for microalgae cultivation, the system can be easily contaminated by other microorganisms [10] or foreign airborne materials like dust and it requires large areas for its construction.

\subsubsection{Photobioreactor}

A photobioreactor (PBR) is a reactor that utilizes light as energy source to allow a photosynthetic reaction to take place [2]. A PBR differs from an open pond in that the microalgae are enclosed in a transparent container, in a tubular, bag-type or panel design, placed vertically or horizontally. The PBR can be protected from weather exposure by being installed in a greenhouse construction or placed in the open for direct exposure to sunlight. Being in a greenhouse structure, the PBR receives a reduced amount of solar radiation due to the shading caused by the cover but is protected from the rain, the wind or snow. Depending on the size of the PBR arrangement, a sliding cover greenhouse could be used so as to avoid these problems since the retractable roof could be adjusted to be on or off according to the weather conditions [11]. Some systems besides the solar radiation use additional artificial light to help boost production, and others, usually of smaller size, rely exclusively on artificial lights. The production of low cost, low electricity consumption, LED lamps helped in this direction. A PBR is usually used to produce microalgae biomass under controlled conditions [12]. One of main advantages of PBRs is that with a good control system, they can better match the ideal growth conditions and requirements of microalgae that are strain specific. A PBR allows safer monoculture of microalgae for a long time as the risk of contamination is lower, compared with open raceway ponds that can be easily contaminated by harmful bacteria and other microflora [7, 8]. The robustness of the PBR can be increased by cultivating multi-algae cultures that can be better adjusted to variations in their environment [4].

\subsubsection{General Operation of a PBR}

A PBR is a closed loop system in which microalgae grow in sea- or wastewater that is pumped through the different stages of the system. The most important part of a PBR is where the microalgae is illuminated to absorb solar radiation or artificial light through glass, transparent plastic tubes, bags or plates, so that photosynthesis can occur similar to a greenhouse in land. The water is circulated by a pump from the photosynthesis part of the PBR to the main feeding tank. The feeding tank makes it possible to supply nutrients, vitamins, other necessary chemicals and for $\mathrm{pH}$ correction. The heat exchanger for the temperature control system can be mounted in the feeding tank, so that the microalgae are not directly subject to adverse temperature variations. The $\mathrm{CO}_{2} /$ air mix is supplied through nozzles discharging in the photosynthesis part of the PBR, promoting at the same time the motion of microalgae in the system. Harvesting takes place through a bypass valve in the system, leading the microalgae suspension through a filter or centrifuge system that extracts the microalgal biomass from the water. The remaining water is then directed to the feeding tank to be treated and sent back to the photosynthesis part. The harvested microalgae mass, in a paste form, can then be processed further after drying.

\subsection{Temperature Control}

Open ponds, which are usually not artificially heated, are limited by low temperatures in the morning, while PBRs in warm days require cooling at midday. For this reason, different methods are used to deal with the temperature control of PBRs [6]. Shading, immersion in a water bath and water spraying are the most common methods to prevent outdoor PBRs from overheating [6]. Shading of the PBR, however, reduces the photosynthetic activity of microalgae, and this leads to a decrease in productivity [6]. Cooling by immersion in a water bath, by evaporative cooling, or by water spraying could be effective in dry climates but it raises the water footprint of the system [6]. Besides, in dry climates like the Mediterranean countries, there is a problem with water availability. Using sea water for this application is not recommended due to the corrosion problems it causes and possible soil pollution in offshore systems. Heat exchangers could be used so that warm water can be utilized for heating of PBRs, although they increase the cost of the system [6]. Warm water can be produced in boilers burning fossil fuels like diesel or natural gas, by utilizing geothermal energy or solar energy, or using waste heat from industrial applications.

\subsection{Scale Up or Scale Down of Photobioreactors}

The level of difficulty of scaling up a PBR is proportional to the type and size of the system and to the heating and shear stress tolerances of the microalgae strains [13]. When scaling up a PBR, illumination, gas exchange rate, mixing mode and temperature control need to be taken into consideration [14]. For every case a suitable design of a PBR has to be applied 
based on the indicative results given by the pilot operation of a small scale model [15]. Non-tubular PBR designs, such as vertical sleeves, airlift columns and flat panels, generally face serious limitations when their volume exceeds 50-100 L, since beyond this limit light energy reaching the microalgae is excessively reduced and gas transfer becomes limited [16]. PBRs can be scaled up by adding more modules or in the case of tubular PBRs by increasing the length and diameter of tubes within certain limits [15].

Mass transfer rate and turbulence in PBR depends on culture velocity that is usually kept between 0.2 and $0.3 \mathrm{~m} / \mathrm{s}$ [6]. The permissible velocity is also depending on the microalgae strain, since shear sensitive microalgae can withstand only certain magnitudes of turbulence. The power requirement for circulation is closely dependent on culture velocity, thus, minimizing velocity will reduce power consumption [17]. Too high velocities could damage the microalgae cells, while too low circulation velocities will eliminate turbulence necessary for effective mixing to occur in the plates of the PBR $[17,18]$ and limit the removal of the photosynthetic generated $\mathrm{O}_{2}$ from the system. The uniformity of temperature throughout the PBR volume is also affected by the circulation velocity and hot or cold pockets could be formed within the culture.

The specific objective of this study was to evaluate the best temperature control system for algae cultivation in flat-panel airlift PBRs by developing a dynamic simulation tool. The simulation provides fundamental data for planning the best temperature control system of commercial microalgae production plants, like the yearly fossil fuel required for a certain geographic location with known climatic data.

\section{Results and Discussion}

\subsection{Determination of Tset and Thermal Behaviour of the System}

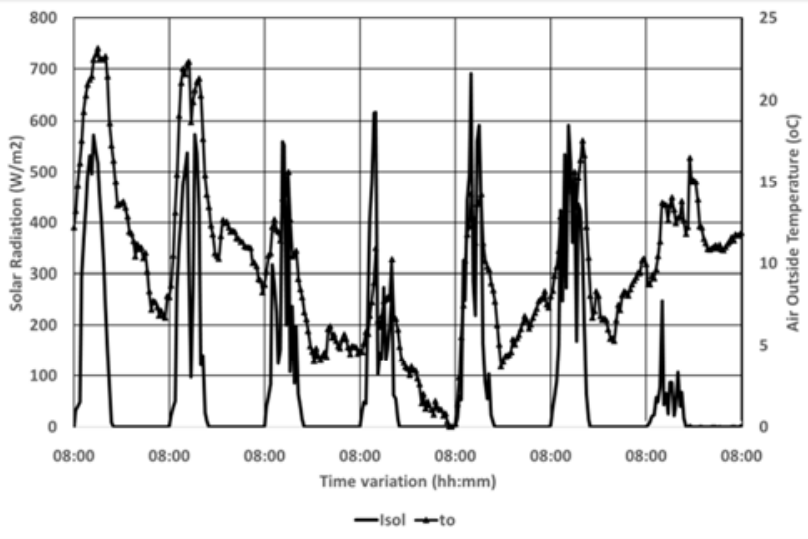

Figure 1. Measured solar radiation on a horizontal plate and recorded ambient temperature for the week 29/12/2015 to 4/1/2016 at Zygi, used for the comparison of the $t_{\text {set }}$ methods.

The three methods for $t_{\text {set }}$ determination were investigated in the simulation model so as to determine the respective fuel consumption for each method and then indicate the most economic one. Figure 1 shows the measured climatic data for the week $29 / 12 / 2015$ to $4 / 1 / 2016$ at Zygi, used for the comparison of the $t_{\text {set }}$ methods. This period was used because it includes both low and higher values for $I_{\text {sol }}$ and $t_{0}$.

The results for $t_{\text {set }}$ variation within the set period are shown in Figure 2. The three methods are comparatively displayed. Fixed limits and Step adjustment are very close to each other but Step adjustment is kept within lower limits making it more economical. Continuous tset adjustment varies considerably between the upper and lower limits and in this way a discomfort within the culture could be caused that could lower the production rate of microalgae.

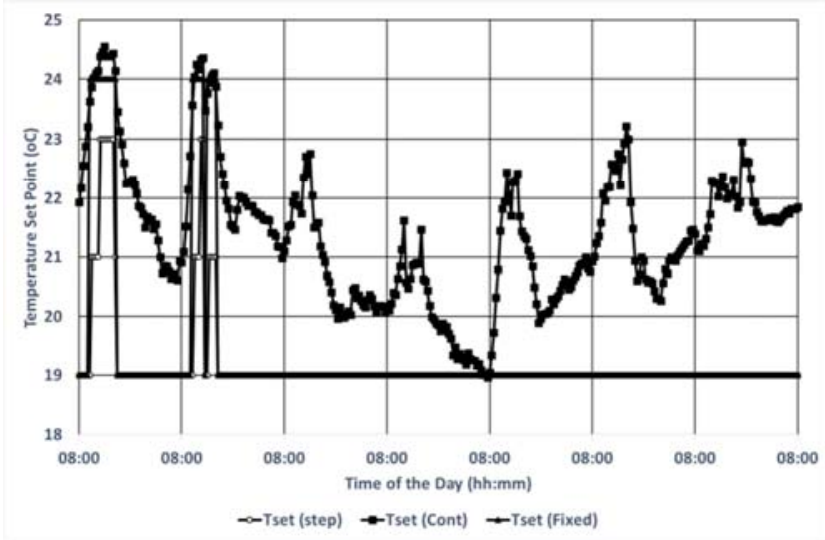

Figure 2. Comparison of the calculated Set temperatures for the week 29/12/2015 to 4/1/2016 at Zygi, for the three $t_{\text {set }}$ methods.

The temperature of the culture in the PBR is shown in Figure 3. The temperatures follow the pattern of the respective $t_{\text {set }}$. The variation of $t_{\text {set }}$ causes, as expected, an effect on the fuel consumption for heating, and thus on the economy of the PBR operation. This effect is shown in Figure 4 that presents the comparison of the Fuel Consumption Ratios of the three methods. The Fuel Consumption Ratio is the amount of fuel needed for heating for a unit PBR culture volume per day. The step control method is shown to be the least fuel consuming method with a Fuel Consumption Ratio of $1.77 \mathrm{~L} / \mathrm{m}^{3} /$ Day. The Continuous $t_{\text {set }}$ adjustment seems to be $26 \%$ more fuel consuming, while the Fixed Limits method results in 2,8\% more fuel consumption.

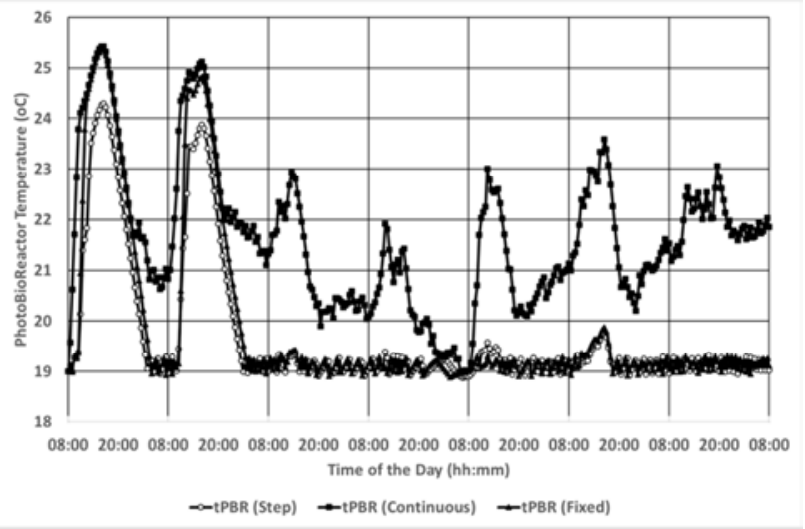

Figure 3. Comparison of the PBR temperatures for the week 29/12/2015 to 4/1/2016 at Zygi, for the three $t_{\text {set }}$ methods. 


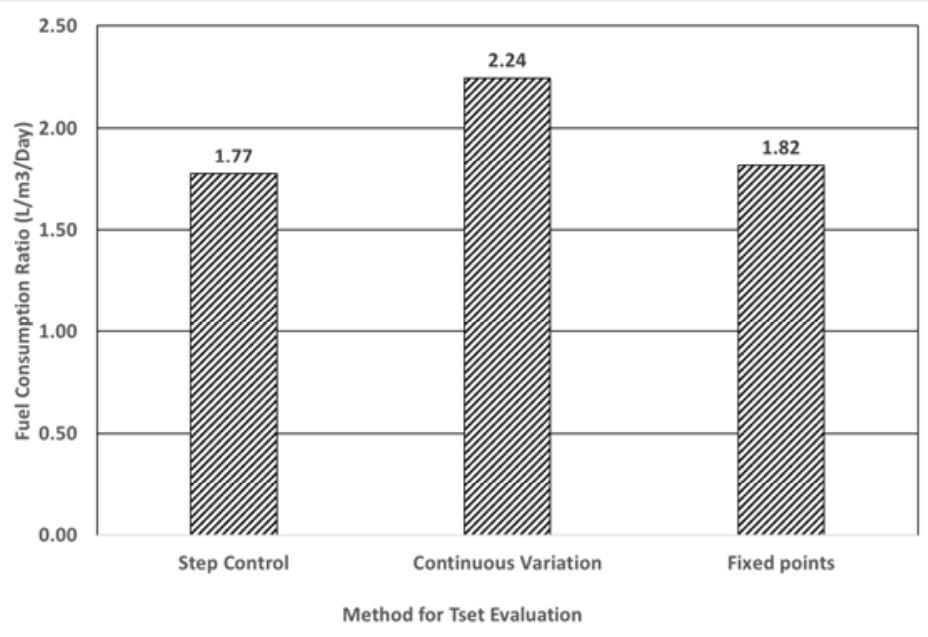

Figure 4. Comparison of the Fuel Consumption Ratios of the three $t_{\text {set }}$ methods, for the week 29/12/2015 to 4/1/2016 at Zygi.

The sensitivity of the energy needed to heat the culture medium to the overall heat transfer coefficient, $U$, of the transparent panels of the PBR is given in Figure 5. The heating energy can be expressed in two forms, the Fuel consumption ratio in $\mathrm{L} / \mathrm{m}^{3} /$ Day that gives the amount of fuel in litres per unit volume of culture medium per day and the Energy Consumption Ratio in $\mathrm{kWh} / \mathrm{m}^{3} /$ Day that gives the energy needed per unit volume of culture medium per day.

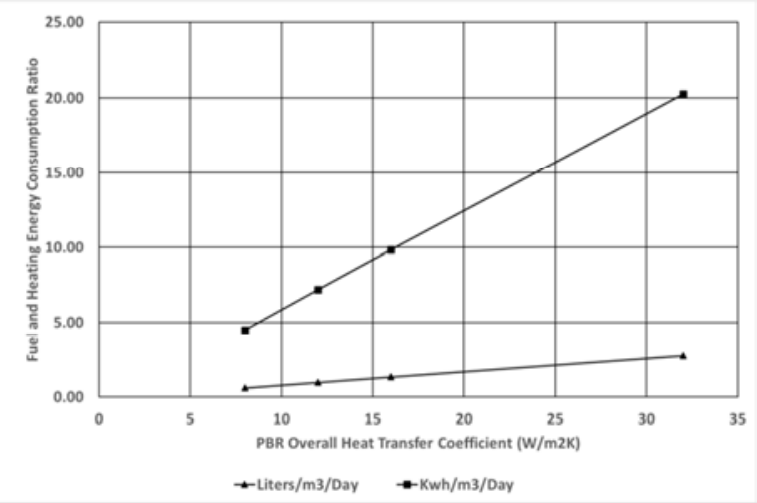

Figure 5. Variation of The Fuel and Heating Energy Consumption Ratio of the PBR, in relation to the Overall Heat Transfer Coefficient of the transparent panels of the PBR for the period 07/11/2015 to 5/04/2016.

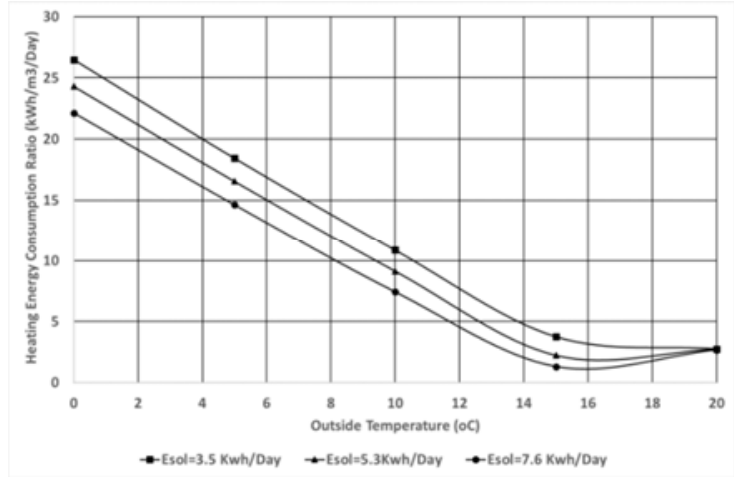

Figure 6. Variation of The Heating Energy Consumption Ratio of the PBR, in relation to the Outside Temperature and the Daily Solar Energy on a Horizontal Surface.
The energy needed for heating depends also on the amount of solar energy received during the day. This dependency is shown in Figure 6 that presents the variation of the Heating Energy Consumption Ratio with the outside temperature, according to the solar energy levels received during the day.

\subsection{Calculation of Burner on Ratio}

As a result of the simulation Model, Table 1 shows the Variation of Burner On Ratio with Outside Temperature for an Overall Heat Transfer Coefficient of $12 \mathrm{~W} / \mathrm{m}^{2} / \mathrm{k}$. Further, Figure 7 shows the variation of the Burner ON Ratio with the outside temperature and the height of solar irradiation during the day.

Table 1. Variation of Burner On Ratio with Outside Temperature.

\begin{tabular}{ll}
\hline $\mathbf{t}_{\mathbf{0}}\left({ }^{\circ} \mathbf{C}\right)$ & Burner ON Ratio \\
\hline 5 & 0.2851 \\
10 & 0.1788 \\
15 & 0.0693 \\
19 & 0.0032 \\
20 & 0.0276 \\
21 & 0.0216 \\
23 & 0.0362 \\
25 & 0.0430 \\
\hline
\end{tabular}

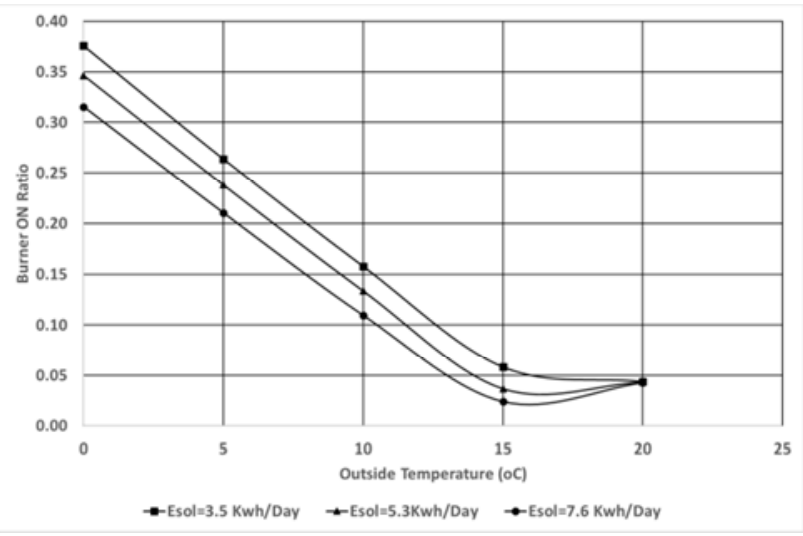

Figure 7. Variation of the Burner ON Ratio of the PBR, in relation to the Outside Temperature and the Daily Solar Energy on a Horizontal Surface. 
For the Zygi region in which the simulated PBR is located, the Degree days per month for the Year 2018 at different temperatures are shown in Table 2. The total Burner operation time is calculated using Equation 8 and the Burner On Ratio indicated in Table 1, for a temperature below $25{ }^{\circ} \mathrm{C}$, to be 178.1 Degree Days or 1424.9 Degree Hours. Then the evaluation of the Yearly Oil consumption of the PBR is calculated to be 583 Litres/Year $/ \mathrm{m}^{3}$.

Table 2. Example of Yearly Oil consumption of the PBR based on the Boiler ON Ratio.

\begin{tabular}{|c|c|c|c|c|c|c|c|c|c|c|}
\hline \multirow{3}{*}{ Month } & \multicolumn{8}{|c|}{ Degree Days for Heating for Year 2018 at Zygi (HDD) } & \multirow{3}{*}{$\begin{array}{l}\left.\text { Burner Operation Time (HDD }{ }_{\text {on }}\right) \\
\text { (Degree Days) }\end{array}$} & \multirow{3}{*}{$\begin{array}{l}\text { Burner Operation Time } \\
\text { (hrs) }\end{array}$} \\
\hline & \multicolumn{8}{|c|}{ Target Temperature } & & \\
\hline & $\mathbf{0}$ & 5 & 10 & 15 & 19 & 21 & 23 & 25 & & \\
\hline JAN & 0 & 0 & 10 & 78 & 181 & 242 & 304 & 366 & 39.16 & 313.27 \\
\hline FEB & 0 & 0 & 3 & 46 & 127 & 181 & 237 & 293 & 28.12 & 224.96 \\
\hline MAR & 0 & 0 & 0 & 28 & 91 & 141 & 200 & 261 & 23.93 & 191.46 \\
\hline APR & 0 & 0 & 0 & 6 & 39 & 68 & 106 & 156 & 14.01 & 112.12 \\
\hline MAY & 0 & 0 & 0 & 0 & 4 & 12 & 29 & 59 & 6.27 & 50.17 \\
\hline JUN & 0 & 0 & 0 & 0 & 0 & 1 & 8 & 25 & 3.02 & 24.13 \\
\hline JUL & 0 & 0 & 0 & 0 & 0 & 0 & 1 & 7 & 0.88 & 7.06 \\
\hline AUG & 0 & 0 & 0 & 0 & 0 & 0 & 0 & 4 & 0.52 & 4.13 \\
\hline SEP & 0 & 0 & 0 & 0 & 0 & 0 & 6 & 20 & 2.46 & 19.65 \\
\hline OCT & 0 & 0 & 0 & 0 & 9 & 20 & 43 & 76 & 7.55 & 60.41 \\
\hline $\mathrm{NOV}$ & 0 & 0 & 0 & 6 & 50 & 88 & 136 & 192 & 16.56 & 132.50 \\
\hline DEC & 0 & 0 & 4 & 49 & 19 & 188 & 312 & 312 & 35.64 & 285.08 \\
\hline Total & & & & & & & & 1771 & 178.1 & 1424.9 \\
\hline \multicolumn{10}{|c|}{ Yearly Oil Consumption per PBR unit volume (Liters/Year $/ \mathrm{m}^{3}$ ) } & 583 \\
\hline
\end{tabular}

Following the same procedure, a comparison can be shown, in Table 3, among the Rated Yearly Oil Consumption for different locations in the Mediterranean, provided the same assumptions apply for the simulation Model.

Table 3. Comparison of Yearly Oil consumption of the PBR based on the Boiler ON Ratio for different locations in the Mediterranean.

\begin{tabular}{llll}
\hline Location & HDD below 25 ${ }^{\circ} \mathbf{C}$ & Burner Operation Time (DD) & Rated Yearly Oil Consumption (Litres/Year/m $^{\mathbf{3}}$ ) \\
\hline Zygi (Cyprus) & 1771 & 178.1 & 583 \\
Heraklion (Crete/Greece) & 2122 & 202.3 & 662 \\
Marsaxlokk (Malta) & 2170 & 200.1 & 655 \\
Kairouan (Tunisia) & 2006 & 200.5 & 656 \\
Malaga (Spain) & 2568 & 271.5 & 888 \\
\hline
\end{tabular}

\section{Materials and Methods}

The present work is based on a design of a Flat-Plate panel PBR with a total culture volume of $51 \mathrm{~m}^{3}$ (Figure 8). It consists of 20 transparent panels of dimensions $2 \mathrm{~m}$ height, $40 \mathrm{~cm}$ wide and $2.5 \mathrm{~m}$ long each. The Flat-Plate panels are considered to be properly supported by a metal frame that prevents their collapse due to the water pressure. Each panel has a volume of $2 \mathrm{~m}^{3}$. The total volume of panels is $40 \mathrm{~m}^{3}$. The water is circulated by a pump from the panels of the PBR to the main feeding tank that has a volume of $10 \mathrm{~m}^{3}$. The main transport pipes are made of a 4 " Schedule 80 PVC Pipe, made of durable, industry approved PVC material. The inside diameter is in average about $96.16 \mathrm{~mm}$. With a pump flow of $8 \mathrm{~m}^{3} / \mathrm{hr}$, $\mathrm{P} 1$ and $\mathrm{P} 2$ in Figure 8, it results to a culture velocity of $0.3 \mathrm{~m} / \mathrm{s}$. The volume of the forward and return pipes is about $1 \mathrm{~m}^{3}$ that is taken into account in the calculations as well. All piping is considered to be thermally well insulated and the heat loss is not taken into account. The flow of culture, therefor, in and out of each panel is $0.4 \mathrm{~m}^{3} / \mathrm{hr}$. At the Panel inlets there are pressure regulating gate valves installed that ensure a uniform flow in each Panel. Similarly, at the outlets of the Panels the installed gate valves enable the individual isolation of each Panel in case it is needed for cleaning or repairing.
The panels are located in 4 rows having 5 panels each (Figure 8). The distance between rows is considered to be $2 \mathrm{~m}$. At Zygi area in Cyprus, the location chosen for the study, Latitude: 34.72.878 and Longitude: 33.33.773, the Solar Angle varies through the year between 32 degrees in Winter (December) and 78 degrees in Summer (June). In order to avoid overshadowing of the panels they were placed in a distance of $3.2 \mathrm{~m}$ from each other facing South so as to receive the maximum solar irradiation possible on their vertical surface. Allowing about $4 \mathrm{~m}$ space around the system for free access and installation of the necessary accessories, auxiliaries, etc. the site area for the whole system is calculated to be $575 \mathrm{~m}^{2}$. The Volume-to-land-area ratio of the system is 88.7 $\mathrm{L} / \mathrm{m}^{2}$. The total surface to volume ratio of the system amounts to $11.27 \mathrm{~m}^{-1}$.

Each panel is considered to have 15 air supply nozzles placed evenly spaced at the bottom with an air supply of 8.2 $\mathrm{L} / \mathrm{min}$ each. Another similar 75 Nozzles are placed in the Feed tank so that in total there are 375 nozzles installed with a total air supply of $3075 \mathrm{~L} / \mathrm{min}$ offering an aeration rate of 0.06 $\mathrm{v} / \mathrm{v} / \mathrm{min}$ to the PBR. The aeration rate is considered to be constant throughout the 24 -hour period. In practice it could be variable through day and night according to the $\mathrm{O}_{2}$ generated in the PBR.

The shell area of each panel is $14 \mathrm{~m}^{2}$ and one third of it is 
considered to be available to direct solar irradiation for calculation purposes. The total shell area of the whole PBR would be therefore $280 \mathrm{~m}^{2}$. The transmission coefficient, $\tau_{\mathrm{r}}$, of solar radiation through the transparent panel material is considered to be 0.7 and from this $40 \%$ is considered to be transformed into heat $\left(\varepsilon_{\mathrm{h}}=0.4\right)$. The solar energy for winter months falling on a vertical panel would be around 1.45 times the measured radiation on a horizontal plate $(\theta=1.45)$ applying the method of Baklouti et al [19] for the Area of Zygi. The calculations were carried out assuming an Overall Heat Transfer Coefficient, U, equal to $12 \mathrm{w} / \mathrm{m}^{2} / \mathrm{k}$ and a volume for the intermediate hot water storage vessel, V1, of $2 \mathrm{~m}^{3}$.

The system was then evaluated considering the above assumptions and parameters.

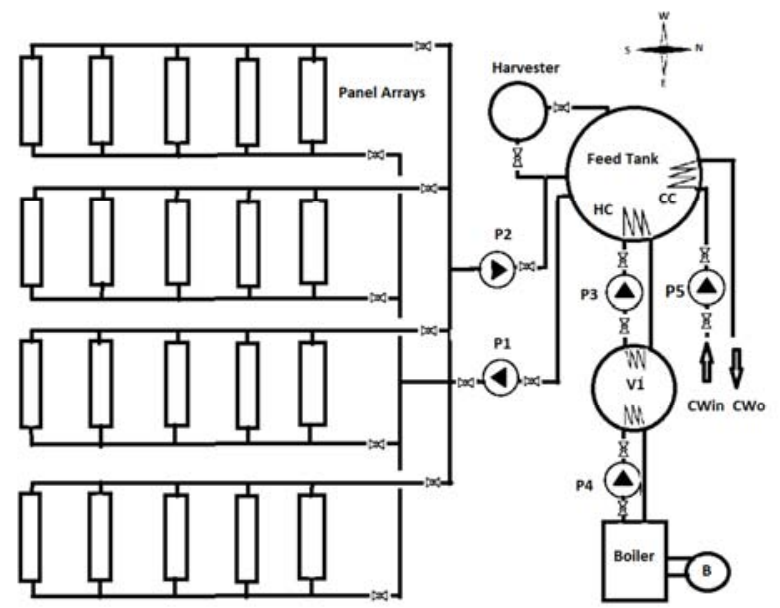

Figure 8. Schematic, not in scale, drawing of the PBR system.

\subsection{Estimation of the PBR Culture Medium Set Temperature}

The present numerical study aims at the investigation of the thermal behaviour of the PBR system from the engineering point of view, giving an indication of the Fuel consumption necessary so that the desired temperatures in the culture medium are kept. The temperature management should guarantee the optimum temperature level in the culture and try at the same time to keep the energy demand of the process as low as possible. The fuel considered in the process is heating diesel with a lower calorific value of $42.496 \mathrm{~kJ} / \mathrm{kg}$ and a density of $0.85 \mathrm{~kg} / \mathrm{l}$.

The heating oil is burned in a $180 \mathrm{~kW}$ water boiler with an efficiency of $87 \%$ and the heat is stored in an intermediate hot water tank, V1, so as to be readily available when requested. Subsequently, the heat is distributed at demand to the culture medium in the Feed Tank of the PBR through a Heat exchanger and a water pump, $\mathrm{P} 3$, at a flow rate of $1.1 \mathrm{~m}^{3} / \mathrm{h}$. Then, the culture medium is circulated to the transparent panels as described above.

The cooling is considered to be done through well or see water that circulates through a heat exchanger in the Feed Tank by a pump, P5, at a volume rate of $6 \mathrm{~m}^{3} / \mathrm{hr}$ and has a constant inlet temperature of $18^{\circ} \mathrm{C}$. The set point for cooling is considered for this work to be between 25 and $26^{\circ} \mathrm{C}$ and depends again on the outside temperature. More precisely, if $\mathrm{t}_{\mathrm{o}}>24^{\circ} \mathrm{C}$ and TPBR $>24^{\circ} \mathrm{C}$, then $\mathrm{t}_{\text {set }}$ is set to $26^{\circ} \mathrm{C}$ else it is set to $25^{\circ} \mathrm{C}$. This is chosen so that the energy needed for cooling is kept low whilst the culture temperature in the PBR remains within the optimal zone.

The energy balance in the PBR, assuming homogenous temperature distribution and no temperature stratifications, would be described by the following simplified equations:

$$
\begin{aligned}
& \dot{Q_{\text {tn }}}-\dot{Q_{0 u t}}=\frac{\mathrm{d} Q_{P B R}}{d \tau} \\
& \dot{Q_{\text {tn }}}=\dot{Q_{s o l}}+\dot{Q_{t r}}+\dot{Q_{h}} \\
& \dot{Q_{s o l}}=I_{s o l} \theta A_{p} \tau_{r} \varepsilon_{h} \\
& \dot{Q_{t r}}=U A\left(t_{o}-t_{P B R}\right) \\
& \dot{Q_{h}}=\dot{m}_{w} c_{p}\left(t_{h}-t_{P B R}\right) \\
& \dot{Q_{o u t}}=\dot{Q_{t r}}+\dot{Q_{c}} \\
& \dot{Q_{c}}=m_{w c} c_{p}\left(t_{P B R}-t_{c}\right)
\end{aligned}
$$

The energy stored in the culture medium of the PBR is given as:

$$
Q_{P B R}=\rho_{w} V_{P B R} c_{p}\left(t_{P B R}\right)
$$

Substituting equations (2) to (7) into equation (1) gives the variation of the temperature in the $\mathrm{PBR}, \mathrm{T}_{\mathrm{PBR}}$, to be:

$$
\frac{d\left(t_{P B R}\right)}{d \tau}=\frac{\dot{Q_{\text {in }}-Q_{\text {out }}}}{\rho_{w} c_{p} V_{P B R}}
$$

or

$$
t_{P B R}=\int \frac{Q_{\text {in }}-Q_{\text {out }}}{\rho_{w} c_{p} V_{P B R}} d \tau
$$

The solution of the above equations is done within the Simulink simulation model.

The costliest operation is heating that depends on the temperature level chosen for the culture. In order to study the influence of the temperature control management scheme on the fuel consumption of the process, three methods for calculating the set temperature, $t_{\text {set }}$, for the heating system were examined.

1. Fixed limits for $\mathrm{t}_{\text {set }}: 19^{\circ} \mathrm{C}<\mathrm{t}_{\text {set }}<24^{\circ} \mathrm{C}$. That means $\mathrm{t}_{\mathrm{set}}=19^{\circ} \mathrm{C}$ for outside temperatures below $19^{\circ} \mathrm{C}$ and $\mathrm{t}_{\text {set }}=$ $24^{\circ} \mathrm{C}$ for outside temperatures above $19^{\circ} \mathrm{C}$.

2. Continuous $t_{\text {set }}$ adjustment according to the outside temperature, allowing its variation again between 19 and $24^{\circ} \mathrm{C}$, but following the equation:

$$
t_{\text {set }}=19+0.24 t_{o}
$$

3. Step adjustment of $t_{\text {set }}$ according to the outside temperature and varying again, in certain steps, between 19 and $24^{\circ} \mathrm{C}$. In this way a more stable temperature fluctuation is achieved in the culture medium avoiding the sudden temperature changes observed by the continuous set point calculation method that could stress 
the microalgae. By this method, the temperature range between the minimum and maximum allowed temperatures is divided in 4 steps as shown in the following Table:

Table 4. Step adjustment of tset in relation to the outside temperature.

\begin{tabular}{ll}
\hline Outside Temperature Range $\left({ }^{\circ} \mathbf{C}\right)$ & Set Temperature $\left({ }^{\circ} \mathbf{C}\right)$ \\
\hline Below 20 & 19 \\
$20-22$ & 21 \\
$22-24$ & 23 \\
Above 24 & 24 \\
\hline
\end{tabular}

Then the performance of the PBR system in respect to its thermal behaviour was further investigated for the best $t_{\text {set }}$ calculation method.

\subsection{The Burner on Ratio (Bon)}

A very useful tool for the estimation of the annual fuel consumption for heating the PBR system is the introduction of a new term in the literature, the Burner ON Time Ratio that gives the time the burner of the heating boiler is on, in relation to the heating period in which heating is needed. If the heating boiler is properly designed and is not under- or oversized, then during the time that the temperature of the PBR medium is lower than the set temperature the burner is periodically switched on and off until the set temperature is reached. The $\mathrm{B}_{\text {on }}$ is the total time that the burner is on, divided by the total time that the temperature in the PBR is lower than the set temperature.

From the meteorological data of a place the Degree Hours (DH), or Degree Days (HDD) for heating can be calculated $[20,21]$. These are the number of hours or days that are recorded to be lower than a certain base temperature. For every month the operation time of the burner for heating is calculated taking in account the $\mathrm{B}_{\text {on }}$ at certain temperature intervals as follows in equation 12 :

$$
\begin{aligned}
& \text { HDDon }=\text { Bon }(5) * \text { HDD5 }+ \text { Bon }(10) *(\text { HDD10 - } \\
& \text { HDD5) }+\operatorname{Bon}(15) *(\text { HDD15 - HDD10) }+ \text { Bon(19)* } \\
& (\text { HDD19 - HDD15) }+ \text { Bon(20) } *(\text { HDD20 - HDD19) }+ \\
& \operatorname{Bon}(21) *(\text { HDD21 - HDD20) }+\operatorname{Bon}(23) *(H D D 23- \\
& \text { HDD21) }+\operatorname{Bon}(24) *(\text { HDD24 - HDD23) }
\end{aligned}
$$

The more temperature intervals for HDD available, the more is the precision of the estimation obtained. The total $\mathrm{B}_{\text {on }}$, in $\mathrm{DD}$, multiplied by 24 gives the total operation time of the burner within the year, in hours. The yearly total burner oil consumption is then calculated by multiplying the total operation time of the burner to the hourly fuel consumption of the burner that is $18,15 \mathrm{~kg} / \mathrm{hr}$. The Rated Yearly oil consumption is calculated by dividing the total oil consumption in Litres, by the culture volume of the system in $\mathrm{m}^{3}$.

The model was constructed using the Simulink toolbox, version 2018b, that runs in a MATLAB environment provided by Mathworks, Inc.

The weather data used in the simulation were real data collected at the Research Station of the Agricultural Research
Institute of Cyprus at Zygi for the years 2015 and 2016.

\section{Conclusions}

The performance of a flat-panel airlift photobioreactor was examined by the use of a simulation program that describes the operation of the system. Three methods were compared for the estimation of the set temperature of the heating boiler: The temperature control between two Fixed limits, the Continuous tset adjustment according to the outside temperature, and the Step adjustment of tset according to the outside temperature. The method of Step adjustment is shown to be the best regarding the economy of the system and the variation of the temperature in the culture medium is kept within the desired limits for avoiding stress in the culture. It is shown that the method can be used to evaluate the heating requirements needed for the evaluation of the fuel consumption of the system and thus the fuel cost estimation of the PBR. For a PBR with a culture volume of $51 \mathrm{~m}^{3}$ and an Overall Heat Transfer Coefficient of $12 \mathrm{~W} / \mathrm{m}^{2} / \mathrm{K}$, a Fuel Consumption Ratio of $1.77 \mathrm{~L} / \mathrm{m}^{3} /$ Day or an Energy Consumption Ratio of 7.20 $\mathrm{kWh} / \mathrm{m}^{3} /$ Day was estimated. The dependency of these values on the Overall Heat Transfer Coefficient of the Panels and the Solar Irradiation during the day was demonstrated. The Burner ON Time Ratio $\left(B_{\text {on }}\right)$ that gives the time in which the burner of the heating boiler is on, in relation to the heating period in which heating is needed, was introduced as a very useful tool for the estimation of the annual fuel consumption for heating the PBR system. The use of this ratio can be expanded in other heating systems, like those in greenhouses, buildings, etc., if properly adjusted according to the time constant of the system. If the heating boiler is properly designed and is not under- or oversized, then during the time that the temperature of the PBR medium is lower than the set temperature, the burner is periodically switched on and off until the set temperature is reached. The $\mathrm{B}_{\text {on }}$ is the total time that the burner is on, divided by the total time that the temperature in the PBR is lower than the set temperature. Knowing the Degree Hours (DH) for heating, at a certain temperature, that can be calculated from the meteorological data of a place, then it is easy to calculate the actual time that the burner is working during the year by multiplying the $\mathrm{DH}$ by the $\mathrm{B}_{\text {on }}$. The evaluation of the Yearly Oil consumption of the PBR for the year 2018 was calculated in this work, based on the developed Burner On Ratio method, to be 583 Litres $/$ Year $/ \mathrm{m}^{3}$. The results can be used for a step down and step up sizing of a PBR in different locations with known meteorological data, such as Cyprus, Crete, Malta, Tunisia and Spain.

\section{Acknowledgements}

The work was done within the "Mediterranean Sea Basin Programme", European Neighbourhood Policy and of its financing instrument (ENPI) for 2007-2013, through the Project: "Production of biodiesel from Algae in selected Mediterranean Countries - Medalgae", with reference number I-B/2.2/099. 


\section{List of Symbols}

A Shell Area of the PBR $\left(\mathrm{m}^{2}\right)$

$\mathrm{A}_{\mathrm{p}}$ Area of the PBR absorbing direct Solar Energy $\left(\mathrm{m}^{2}\right)$

$\mathrm{B}_{\text {on }}$ Burner ON Ratio (-)

$B_{\text {on(i) }}$ Burner ON Ratio for temperature (i). For example:

$\mathrm{B}_{\mathrm{on}(15)}$ is the Burner ON Ratio for a temperature of $15^{\circ} \mathrm{C}$

CC Cooling Coil of Heat Exchanger $\mathrm{K} /]$

$\mathrm{c}_{\mathrm{p}}$ Water specific heat capacity at constant pressure $[\mathrm{J} / \mathrm{kg} /$

CWin Incoming cooling water

CWo Return cooling water

$\mathbb{d} \mathrm{Q}_{\mathrm{PBR}} / \mathrm{d} \tau$ Rate of change of heat content of the culture medium in the PBR with the time $\tau$.

HC Heating Coil of Heat Exchanger

DH Degree Hours

HDD Degree Days for heating with a base temperature equal to the minimum set temperature

$\mathrm{HDD}_{\mathrm{i}}$ Degree Days for a base temperature i, for example: $\mathrm{HDD}_{10}$ are the Degree Days for a temperature of $10^{\circ} \mathrm{C}$.

$\mathrm{HDD}_{\text {on }}$ Duration in Degree Days for which the Burner is actually on (Burner on time).

$\mathrm{I}_{\text {sol }}$ Solar Energy measured on a horizontal plate $\left(\mathrm{W} / \mathrm{m}^{2}\right)$

L Litres

$\dot{Q}_{c}$ Cooling energy flow (W)

$\dot{Q}_{h}$ Heat supply from Boiler $(\mathrm{W})$

$Q_{i n}$ Heat input to the PBR (W)

$Q_{\text {out }}$ Heat Output from the PBR (W)

$\mathrm{Q}_{\mathrm{PBR}}$ Heat content of PBR (J)

$Q_{\text {sol }}$ Solar Heat Input (W)

$Q_{t r}$ Transmission Heat Losses from the PBR (W)

$m_{w}$ Rate of flow of heating water $(\mathrm{kg} / \mathrm{s})$

$m_{w c}$ Rate of flow of cooling water $(\mathrm{kg} / \mathrm{s})$

$t_{c}$ Temperature of cooling water $\left({ }^{\circ} \mathrm{C}\right)$

$t_{h}$ Temperature of heating water $\left({ }^{\circ} \mathrm{C}\right)$

$\mathrm{t}_{\mathrm{o}}$ Outside air (ambient) temperature $\left({ }^{\circ} \mathrm{C}\right)$

$t_{\mathrm{PBR}}$ Temperature of the culture medium in PBR $\left({ }^{\circ} \mathrm{C}\right)$

U Overall Heat Transfer Coefficient $\left(\mathrm{W} / \mathrm{m}^{2} / \mathrm{K}\right)$

Greek Symbols

$\varepsilon_{\mathrm{h}}$ Heat conversion coefficient of solar energy

$\theta$ Multiplier for the Solar Radiation on a horizontal plate to give the irradiation on a vertical surface.

$\tau_{\mathrm{r}}$ Transmission coefficient of solar energy through the transparent surface of PBR

\section{References}

[1] M. K. Lam and K. T. Lee, (2012), "Microalgae biofuels: A critical review of issues, problems and the way forward", Biotechnol. Adv. 30 (3), 673-690.

[2] T. M. Mata, A. A. Martins and N. S. Caetano, (2010), "Microalgae for biodiesel production and other applications: a review", Renew. Sust. Energ. Rev. 14 (1), 217-232.

[3] L. Zhu, (2015), "Microalgal culture strategies for biofuel production: A review", Biofuels Bioprod. Biorefin. 9 (6), 801814.
[4] M. Omirou, I. Tzovenis, P. Charalambous, P. Tsaousis, P. Polycarpou, X. Chantzistrountsiou, A. Economou-Amilli and I. M. Ioannides. (2018). "Development of marine multi-algae culture for biodiesel production”. Elsevier, Algal Research 33, 462-469.

[5] M. Arnold, (2013), "Sustainable Algal Biomass Products by Cultivation in Waste Water Flows", VTT Technology, 147, 1-84.

[6] Tredici, M. R. (2004). "Mass production of microalgae: Photobioreactors". In: Richmond A., editor. Handbook of microalgal culture: biotechnology and applied phycology. Oxford: Blackwell Publishing, 178-214.

[7] I. Rawat, R. R. Kumar, T. Mutanda and F. Bux, (2011), "Dual role of microalgae: Phycoremediation of domestic wastewater and biomass production for sustainable biofuels production", Appl. Energy 88 (10), 3411-3424.

[8] L. Brennan and P. Owende, (2010), "Biofuels from microalgae - A review of technologies for production, processing, and extractions of biofuels and co-products", Renew. Sust. Energ. Rev. 14 (2), 557-577.

[9] P. M. Schenk, S. R. Thomas-Hall, E. Stephens, U. C. Marx, J. H. Mussgnug, C. Posten, O. Kruse and B. Hankamer, (2008) "Second generation biofuels: high-efficiency microalgae for biodiesel production", Bioenergy Res. 1 (1), 20-43.

[10] M. Balat, (2011), "Potential alternatives to edible oils for biodiesel production - A review of current work", Energy Convers. Manag. 52 (2), 1479-1492.

[11] X. Tong, Z. Sun, N. Sigrimis and T. Li. "Energy sustainability performance of a sliding cover solar greenhouse: Solar energy capture aspects". December 2018, Biosystems Engineering 176, 88-102.

[12] Y. Chisti, (2007), "Biodiesel from microalgae", Biotechnol. Adv. 25 (3), 294-306.

[13] M. Olaizola, (2000). "Commercial production of astaxanthin from Haematococcus pluvialis using 25,000-liter outdoor photobioreactors". J. Appl. Phycol., 12, 499-506.

[14] M. Olaizola, (2003). "Commercial development of microalgal biotechnology: from the test tube to the marketplace". Biomolecular Engineering, 20, 459-466. DOI: 10.1016/S1389-0344(03)00076-5.

[15] Chisti, Y., F. G. Camacho, F. G. A. Fernandez and E. M. Grima, (1999). "Photobioreactors: light regime, mass transfer, and scale up". Journal of Biotechnology, 70, 231-247. PII: S0168-1656(99)00078-4

[16] Pulz, O. (2001). "Photobioreactors: production systems for phototrophic microorganisms". Appl. Microb. Biotechnol., 57, 287-93.

[17] N. H. Norsker, M. J. Barbosa, M. H. Vermue and R. H. Wijffels, (2012). "On energy balance and production costs in tubular and flat panel photobioreactors". Technikfolgenabschätzung Theorie und Praxis, 21, 1: 54-62.

[18] C. J. Geankoplis, (2003). "Transport Processes and Separation Process Principles". Upper Saddle River, NJ: Pearson Education Inc.

[19] I. Baklouti, D. Zied and A. Mohamed. (2012). "Estimation of solar radiation on horizontal and inclined surfaces in Sfax", TUNISIA. 2012 1st International Conference on Renewable Energies and Vehicular Technology, REVET 2012. 10.1109/REVET.2012.6195260. 
[20] P. Borah, M. K. Singh and S. Mahapatra. "Estimation of degree-days for different climatic zones of North-East India". Sustainable Cities and Society, Volume 14, February 2015, 70-81.
[21] H. Roger. (1983). "Estimating monthly degree-days". Building Services Engineering Research \& Technology - BUILD SERV ENG RES TECHNOL. 4,.159-162. 